\title{
Assessing the Value of Wind Generation in Future Carbon Constrained Electricity Industries
}

\author{
Peerapat Vithayasrichareon* and Iain F. MacGill
}

School of Electrical Engineering and Telecommunications and Centre for Energy and Environmental Markets, University of New South Wales, Sydney, Australia

\footnotetext{
* Corresponding author: School of Electrical Engineering and Telecommunications, University of New South Wales, Sydney, NSW 2052, Australia

Tel: + 6129385 4061, Fax: + 6129385 5993, E-mail: peerapat@unsw.edu.au
}

\begin{abstract}
This paper employs a novel Monte-Carlo based generation portfolio assessment tool to explore the implications of increasing wind penetration and carbon prices within future electricity generation portfolios under considerable uncertainty. This tool combines optimal generation mix techniques with Monte Carlo simulation and portfolio analysis methods to determine expected overall generation costs, associated cost uncertainty and expected $\mathrm{CO}_{2}$ emissions for different possible generation portfolios. A case study of an electricity industry with coal, Combined Cycle Gas Turbines (CCGT), Open Cycle Gas Turbines (OCGT) and wind generation options that faces uncertain future fossil-fuel prices, carbon pricing, electricity demand and plant construction costs is presented to illustrate some of the key issues associated with growing wind penetrations. The case study uses half-hourly demand and wind generation data from South Eastern Australia, and regional estimates of new-build plant costs and characteristics. Results suggest that although wind generation generally increases overall industry costs, it reduces associated cost uncertainties and $\mathrm{CO}_{2}$ emissions. However, there are some cases in which wind generation can reduce the overall costs of generation portfolios. The extent to which wind penetration affects industry expected costs and uncertainties depends on the level of carbon price and the conventional technology mix in the portfolios.
\end{abstract}

Keywords: Generation portfolio analysis; wind power integration; carbon price.

\section{Introduction}

Wind generation is fast becoming a significant generation source worldwide, and particularly so in some European countries such as Denmark, Germany, Portugal, and Spain, where it is now contributing greater than $10 \%$ of overall electricity generation (EWEA, 2011). With increasing international concern over the threat of global climate change, a growing number of countries have established regulatory frameworks and policies to reduce carbon emissions in their electricity sectors and promote renewable generation. Currently, electricity generation is responsible for approximately $40 \%$ of global $\mathrm{CO}_{2}$ emissions and this contribution is still rising (IEA, 2009a). Renewable generation from sources such as wind is, therefore, increasingly recognised as an important low-carbon complement to existing generation technologies. Furthermore, 
growing uncertainties over future fossil-fuel prices and their availability have heightened concerns over the security of electricity supply in numerous countries and this has also contributed to the recent promotion of renewable generation.

Wind has proven to be one of the most cost effective 'new' (non-hydro) renewable energy options and is the first intermittent energy source to reach significant penetrations in large power systems (MacGill, 2010). Wind energy, however, possesses different characteristics from conventional generation sources due to its highly variable and somewhat unpredictable nature. Given the wind industry's rapid growth, there are increasing concerns regarding the potential operational and economic impacts of incorporating wind generation into power systems (Smith et al., 2007). High wind penetrations increase the complexity of electricity industry operation in terms of generation dispatch and scheduling (Traber and Kemfert, 2011). Furthermore, it also places additional requirements for ancillary services and more sophisticated economic dispatch and unit commitment (Tuohy et al., 2009).

From a planning and investment perspective, which is a main focus of this paper, large-scale deployment of intermittent generation sources such as wind power seems likely to have significant implications for conventional generating plant investment and planning in the industry. In providing highly variable yet very low operating cost generation, wind almost invariably changes the requirements placed on conventional generation capacity to meet electricity demand (Bushnell, 2010).

Currently, numerous countries around the world are also establishing mechanisms to 'price' carbon emissions within the electricity industry. However, there is continuing uncertainty surrounding the longer-term impacts of climate change policies and the level of carbon price likely to be required to deliver effective action on climate change (IEA, 2007; Newcomer et al., 2008). Nevertheless, significant carbon prices are likely to be one of the critical factors in driving future generation investment towards low emission and renewable technologies such as wind power. Beyond present uncertainties regarding climate change policies, increased uncertainties about future fossil fuels prices, fluctuating capital costs for generation plant and recent reductions in demand growth in many countries following the Global Financial Crisis (GFC) have also all increased the challenge for generation investment decision making in the electricity industry.

Wind power is a capital intensive technology but its operating costs are very low due to its 'free' fuel. Furthermore, a carbon price will have no impact on these costs. Although the direct costs of wind power are currently higher than conventional technologies in most countries, it has been suggested that adding wind can help to hedge against fossil fuel and carbon price uncertainty, and therefore reduce the risk of generation portfolios (Awerbuch, 2006; Doherty et al., 2006).

This paper employs a novel generation investment decision support tool developed in Vithayasrichareon and MacGill (2012a) to explore the potential impacts of increasing wind penetrations on the expected cost, associated cost uncertainty and carbon emissions of different future conventional generating plant portfolios. The tool is used to assess the potential performance of different mixes of wind, conventional pulverised coal, Combined Cycle Gas Turbine (CCGT) and Open Cycle Gas Turbine (OCGT) plants 
under future uncertain, coal and gas prices, carbon price, electricity demand and plant capital costs. Of particular interest are the interactions between varied wind penetrations, carbon prices and fossil-fuel plant mix on overall portfolio costs and uncertainties, as well as carbon emissions. This study extends our previous work by incorporating different wind penetrations into possible generation portfolio options.

Section 2 describes the decision support tool used and its application to evaluate generation portfolios that include varied levels of wind generation. Section 3 describes the case study, which is based on wind generation and demand in South Eastern Australia, as well as regional new-build plant and fuel costs. The results and analysis are presented in Section 4 followed by some tentative conclusions on the potential implications and interactions of wind generation and carbon prices on different conventional plant portfolios in Section 5.

\section{Monte Carlo Based Decision-Support Tool for Generation Investment Including Wind Generation}

The generation investment and planning decision-support tool presented in this paper is intended to facilitate policy-makers and planners to gain high-level insights into some of the challenges associated with different wind penetrations and carbon pricing policies in future generation portfolios. Hence, the tool adopts a long-term overall societal perspective where the key concern is how best the electricity industry might meet future demand at lowest societal cost within acceptable levels of risks and environmental constraints (Jansen et al., 2006). Therefore, it focuses on overall industry generation costs without considering issues associated with privately undertaken generation investment within liberalised electricity markets such as strategic behaviors of electricity industry participants. The tool also permits decision-makers to identify future generation portfolios which suit their particular risk preferences and consider wider multi-criterion objectives including industry-wide greenhouse emissions and exposure to different fuel markets.

\subsection{Monte Carlo Model for Assessing Generation Portfolios}

The tool used in this paper extends deterministic load duration curve (LDC) methods for solving optimal generation mixes by incorporating uncertainties for key input cost assumptions through Monte Carlo Simulation (MCS). The tool then applies financial portfolios analysis techniques to determine an efficient frontier of expected overall industry generation costs and associated cost uncertainties for different generation portfolios. The tool determines a probability distribution of overall industry costs and $\mathrm{CO}_{2}$ emissions for each possible generation portfolio from the MCS. Since the technique is based on MCS, it does not depend upon only normal distributions being used to model uncertainties - arbitrarily complex and interacting probability distributions can also be applied (Duenas et al., 2011; Roques et al., 2006; Spinney and Watkins, 1996). For simplicity, log-normal probability distributions are used to represent fuel cost, carbon costs, and plant capital costs in the case study in section 3. Hence the cost spread of each generation portfolio can be represented by a standard deviation (SD) which is referred to, here, as 'cost uncertainty'. It has a similar meaning to 'risk' in the economic and financial 
context. However, the MCS techniques which the tool incorporates provide a rich analytical framework for assessing various risk measures other than variance to suit particular risk preferences.

Although the tool employs an efficient frontier approach to analyse its results that has been previously used in Mean Variance Portfolio (MVP) analysis (Awerbuch, 2006; Huang and $\mathrm{Wu}, 2008)$, the method for obtaining the expected generation portfolios costs and associated cost uncertainties is different. In standard MVP techniques, the expected portfolio cost is calculated from the weighted average of the individual technology costs (based on an assumed capacity factor) in the portfolio while the expected portfolio risk is determined from the weighted average of risks of the individual technology based on their expected correlations and covariances. In our method, by contrast, the expected cost and risks of different generation portfolios are directly obtained from running MCS for several thousand scenarios of uncertain input parameters. With this approach, uncertain parameters which include fuel prices, carbon price, future demand, and plant capital costs are all characterised by user-specified probability distributions. Furthermore, correlations among gas, coal and carbon prices can also be taken into consideration. There is no restriction on using only normal distribution to model these uncertainties as seen with some other approaches - almost any form of distribution can be incorporated through the MCS technique.

Standard portfolio analysis assumes that the portfolio costs or returns are characterised by normal distributions and therefore can be described using only the first two moments, which are mean and variance. However, the distributions of energy commodity prices have been frequently observed to exhibit major deviations from normality due to their asymmetry and tail fatness (Eydeland and Wolyniec, 2003). The tail fatness reflects a greater possibility of rare but extremely high price events, which is one of the major concerns to utility investors and policy makers. Hence, higher moments should, arguably, also be considered in addition the mean and variance in assessing generation portfolios. The possible significance of higher moments is partially reflected in Madlener and Wenk (2008) yet otherwise mostly overlooked in the literature on generation portfolio analysis.

Also, standard MVP analysis is typically carried out using estimated levelised costs of electricity from different generation options. As such, it requires deterministic assumptions on the capacity factor of each technology in the portfolio - assumptions that might not hold for future fuel and carbon prices. Furthermore since the load is not uniform, such assumptions would fall short in recognising the value of different types of generation technology given the tradeoffs between their fixed and variable costs. The importance of this has been recognised for example in Gotham et al. (2009) which decomposes load into various types having different load factors in order to better value their characteristics. Furthermore, estimating the value of intermittent renewable generation technologies, particularly wind, using the levelised cost method is highly problematic because it does not reflect the different values of generation which have greater or lesser intermittency and dispatchability. Whilst the levelised cost of wind and OCGT might be similar, the OCGT is certainly of greater value in ensuring supply meets 
demand at all times. As such, levelised cost comparisons tend to overvalue intermittent generation technologies compared to dispatchable conventional generating units (Joskow, 2010).

The approach presented in our paper does not assume a capacity factor for each generation technology - instead the generation output of each plant type in a portfolio is determined from half-hourly economic dispatch for particular fuel and carbon prices to meet changing demand. Half-hourly wind generation output is simulated based on the actual half-hourly wind generation output from wind farms in South Eastern Australia for a particular reference year, as will be explained in Section 3.

In this tool, for each Monte Carlo run, total generation cost for each generation portfolio is calculated based on each set of correlated sample fuel and carbon prices, capital cost and demand in each period of a LDC. The total generation cost of each portfolio consists of annualised fixed cost and variable costs, and is calculated by

$$
\sum_{n=1}^{N}\left(F C_{n} \times I_{n}\right)+\left(V C_{n} \times E_{n}\right)
$$

where $F C_{n}$ is the annualised fixed cost ( $\left.\$ / \mathrm{MW}\right), I_{n}$ is the installed capacity (MW), $V C_{n}$ is the variable operating cost per unit $(\$ / \mathrm{MWh}), E_{n}$ is the energy $(\mathrm{MWh})$ generated by each technology $n$ in a year, and $N$ is the number of generation technologies considered in a portfolio.

The annualised fixed cost is calculated from the overnight capital cost of each generation technology using the Capital Recovery Factor (CRF) as expressed in Eq. (2) and Eq. (3). The CRF determines the equal amount of regular payments in a present amount of money.

Annualised capital cost $=$ Overnight capital $\operatorname{cost}(\$ / M W) \times C R F$

$$
C R F=\frac{j(1+j)^{m}}{(1+j)^{m}-1}
$$

where $m$ is the plant life and $j$ is the discount rate.

The variable operating cost comprises of operational and maintenance (O\&M), fuel and carbon costs as detailed in Eq. (4) and (5).

$$
\begin{gathered}
\text { Fuel cost }_{n}(\$ / M W h)=\text { Fuel price }_{n}(\$ / G J) \times \text { Average heat rate }_{n}(G J / M W h) \\
\text { Carbon cost }_{n}(\$ / M W h)=E F_{n} \times \text { Carbon price }(\$ / t C O 2)
\end{gathered}
$$

where $E F_{n}$ is the emission factor $\left(\mathrm{tCO}_{2} / \mathrm{MWh}\right)$ of generation technology $n$.

The generation output of each technology in each period of the LDC is determined using partial economic dispatch ${ }^{1}$ with an objective function to minimise operating costs in each period of the LDC subjected to constraints as shown in Eq. (6) - (8).

$$
\text { Minimize } \sum_{n=1}^{N} V C_{n}\left(P_{n}\right)
$$

\footnotetext{
${ }^{1}$ For the partial economic dispatch, transmission network and other inter-temporal operating constraints such as ramp rates and minimum operating levels of generation units are not taken into consideration.
} 


$$
\begin{array}{cc}
\text { subject to } & \sum_{n=1}^{N} P_{n}=D \\
& P_{n} \leq I_{n}
\end{array}
$$

where $V C_{n}\left(P_{n}\right)$ is the variable operating cost (\$) of generating power $P_{n}(\mathrm{MW})$ from technology $n$, (with $I_{n}$ representing the total installed capacity of technology $n$ ), and $D$ is the demand (MW) in each interval of the LDC.

The installed capacity of each technology is calculated from its percentage share of generation portfolio. The total installed capacity is determined based on a specific reliability criterion so that the electricity demand is met for a certain percentage of the time in a year. This is explained in detail in section 3.1. Total $\mathrm{CO}_{2}$ emission of each portfolio in a year is determined based on electrical energy produced and emissions factor or each technology within the portfolio. Outputs from the MCS represent a range of possible annual industry generation costs for each generation portfolio, and can therefore be represented by a probability distribution.

\subsection{Incorporating Wind Generation}

One challenge for standard LDC approaches is the incorporation of variable, nonstorable, and somewhat unpredictable renewable energy resources such as wind and solar into generation portfolios. These standard approaches assume that all plants are dispatchable across their entire output range as required, which is certainly not the case for these renewable technologies.

In this paper, the tool is applied to incorporating wind generation through the use of residual load duration curve (RLDC) techniques where simulated half-hourly wind generation output is subtracted from actual demand over the same time. The resulting residual (net) demand, after accounting for wind generation, is then arranged in descending order of magnitude to obtain a RLDC. It is this curve which has to be met by the conventional generation technologies in the portfolio. Wind power is considered exogenous and treated as negative load given that it has very low operating costs and can offset the need to dispatch conventional fossil-fuel generation (Delarue et al., 2011; Doherty et al., 2006; Ummels et al., 2007). This approach incorporates the variability of wind generation and also captures the actual relationship between typically weather and climate dependent renewable generation sources and electricity demand.

Note that while the use of LDC and RLDC has many advantages, hence their widespread application in investment oriented decision support tools, the approach does remove the chronology (change over time) of demand, and, in this case, also wind. This does involve some limitations in assessing electricity industry operation. Inter-temporal operating constraints including issues such as unit commitment, spinning reserves and ramp rates are not currently included in the tool. However, some of these issues can be incorporated as possible extensions to the method as discussed in De Jonghe et al. (2011). These extensions are further discussed in the conclusion of this paper.

The work in this paper differs to existing literature in a number of aspects. In particular, it explicitly incorporates multiple and interacting uncertainties including fuel and carbon prices, electricity demand and plant capital costs into the analysis of long-term 
generation planning and investment. Furthermore, it incorporates generation portfolio techniques to explore tradeoffs between different criteria that are relevant for policy decision-making.

This paper does not explicitly model uncertainty in wind generation, however it should represent a relatively straightforward extension since the tool already incorporates demand uncertainty, as described in Section 3. In this work, only new-build generation portfolios are assessed without considering existing generating capacity. Nevertheless, the approach taken by the tool can incorporate existing generating plant within possible future portfolios using a similar approach presented in Vithayasrichareon and MacGill (2012b).

\section{Case Study Description}

This paper applies the tool to a case study of an electricity industry with coal, CCGT, and OCGT and wind generation options that faces uncertain future fuel prices, carbon prices, electricity demand and new-build plant capital costs. This study assumes that these fuel prices, carbon price and capital cost uncertainties can be represented by lognormal distributions. This reflects the asymmetric downside risks of such costs. Electricity demand is represented by a LDC and its uncertainty is modeled by assuming a normal distribution of peak demand in a RLDC. Therefore, these uncertain parameters can be described through their mean and SD.

The data for this case study including demand and wind generation, fuel and other costs are based on the actual dispatch data and consultancy studies for the states of South Australia (SA), Victoria (VIC) and Tasmania (TAS) in Australia. All monetary values are shown as Australian dollars. Key uncertain input parameters and their probabilities are modeled based on historical data and independent expert opinion in the literature, as described in Section 3.3. Given that decision-making in generation investment and planning inevitably requires decision-makers forming some views about future drivers such as fuel prices and various cost factors, historical data and expert opinions are often used in the absence of better approaches (Savvides, 1994). Note, however, that this tool does not force tight constraints on the way that future uncertainty is incorporated.

Different levels of wind penetration are simulated for all of the possible range of thermal generating plant portfolios. The proportion of coal, CCGT and OCGT are varied from $0 \%$ to $100 \%$ in $10 \%$ increments resulting in 66 possible combinations of generation portfolios. For each of these generation portfolios, the calculation of overall industry costs and emissions is repeated for 10,000 simulated fuel and carbon prices, demand and capital costs.

\section{1. $\quad$ Expected Demand Profile and Wind Generation Data}

The demand and wind generation data used for the simulation are the actual 30minute data in the state of SA, VIC and TAS in 2009 provided by the Australian Energy Market Operator (AEMO) (AEMO, 2009b). This region was chosen because of the significant wind generation already in place hence it provides a reasonable basis for simulating high wind penetrations. 
The year 2009 was used as a reference year to model total 30-minute wind generation output for different wind penetrations. However, during 2009 the installed wind generation capacity in these three states increased from $960 \mathrm{MW}$ to 1,450 MW. Therefore, in order to accurately model wind generation outputs for different penetrations, the actual wind generation in 2009 has been scaled to reflect the full-year installed wind generation capacity of 1,450 MW. Fig. 1 shows the total simulated wind generation output in these three states in 2009 which also indicates the high variability of the wind generation output.

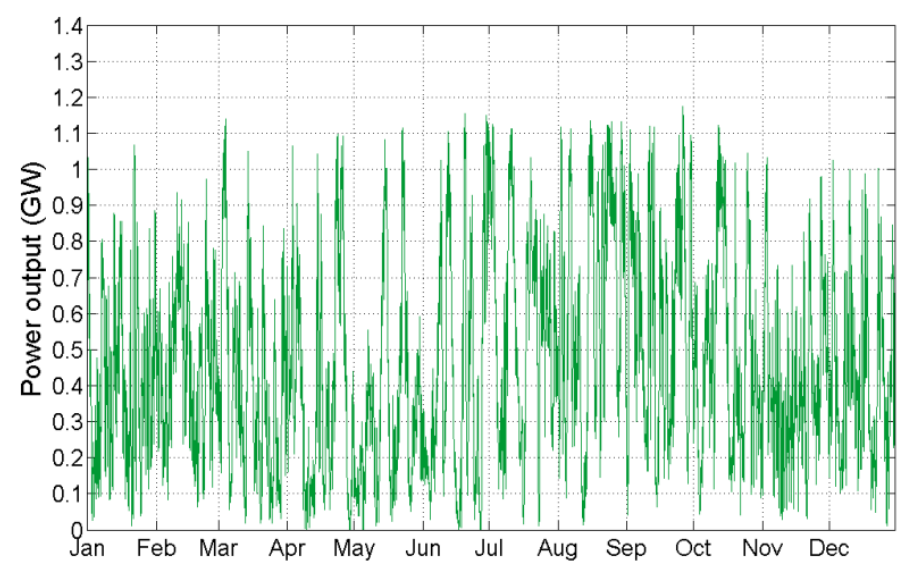

Fig. 1. Simulated wind power output in 30-minute interval in SA-VIC-TAS reflecting the full year installed wind capacity in 2009.

The wind generation profile shown in Fig. 1 is then use as a basis to model for higher wind penetrations than the present $5.2 \%$. Scenarios from $0 \%$ to $25 \%$ wind energy penetration are undertaken in $5 \%$ increments. Note that this approach is likely to overestimate the actual variability of high wind penetrations as one would expect some benefits from diversity with more wind farms (Electricity Supply Industry Planning Council (ESIPC), 2004; Milligan et al., 2009). ${ }^{2}$ Fig. 2 shows the electricity demand and wind power for different simulated wind penetrations in 30-minute intervals.

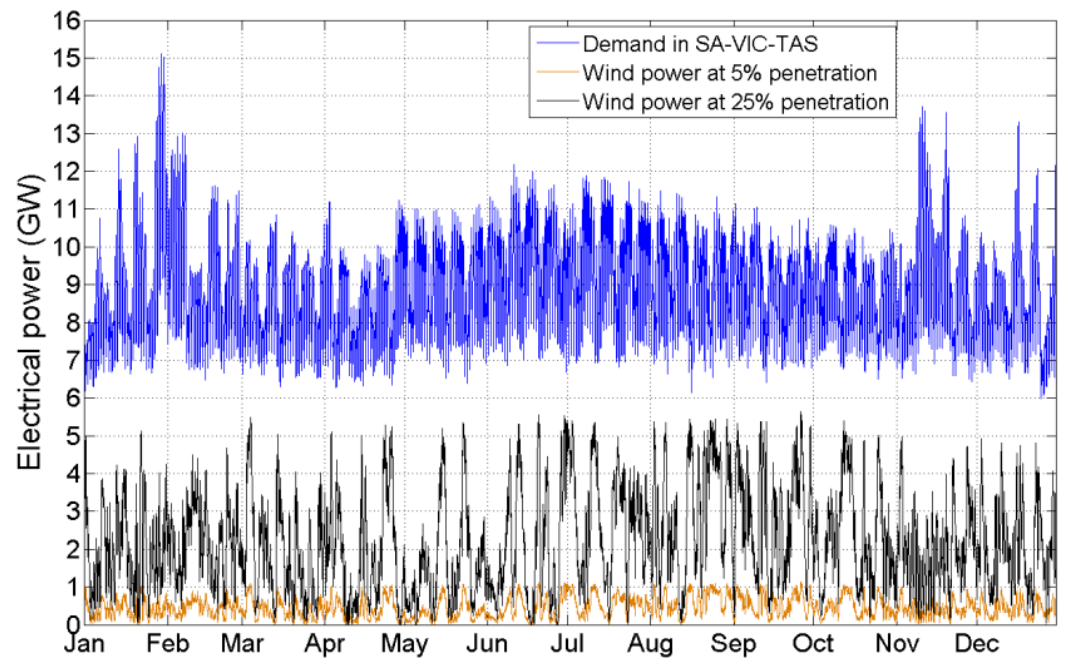

Fig. 2. Demand and wind power output for different penetrations over a year.

Wind generation is modeled as negative load and is therefore subtracted from the

\footnotetext{
${ }^{2}$ This is also likely to underestimate the diversity value of wind generation since other potential wind farm sites in the system are not considered.
} 
half hourly demand over the year to obtain a residual demand profile. This residual demand profile is then rearranged in descending order of magnitude to obtain a Residual Load Duration Curve (RLDC), as shown in Fig. 3. The resulting RLDC is to be served by conventional generation technologies, which in this study are coal, CCGT and OCGT. In order to reduce computational time, the half-hourly LDC and RLDCs are simplified into 876 segments each representing the 10-hour average demand.

Fig. 3 also indicates there was no excess wind generation in any period for the penetration levels in the range of $5 \%$ to $25 \%$ (i.e. total demand always greater than total wind power output), therefore wind generating units are assumed to always generate when available without the need for curtailment. In practice, minimum operating levels, start-up times and costs, and ramp rate limits for thermal plants might necessitate such curtailment.

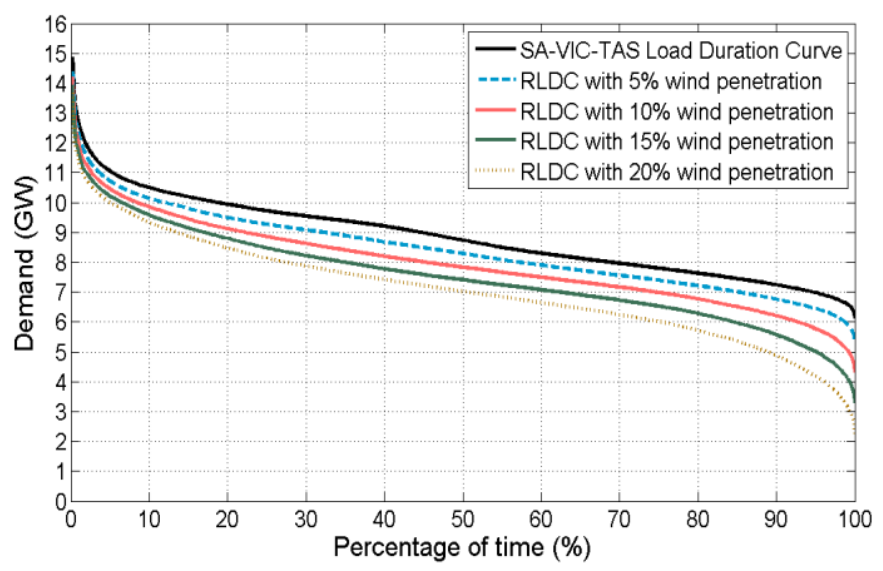

Fig. 3. Residual Load Duration Curves for different wind penetrations.

Demand uncertainty is modeled by assuming a normal distribution of peak demand in the RLDC. The SD of peak demand is approximated based on studies of this region that estimate the likelihood that the maximum demand will exceed projections for any given year using $90 \%, 50 \%$ and $10 \%$ 'probability of exceedance' projections as given in (AEMO, 2009a). The SD of peak demand is approximated to be $4 \%$ of the expected peak demand.

The installed wind capacity for different wind energy penetrations is determined based on a $35 \%$ wind capacity factor, as shown in Eq. (9). Since typical wind capacity factors for the South Eastern Australian region are consistently between $32 \%$ to $40 \%$ (Electricity Supply Industry Planning Council (ESIPC), 2004). ${ }^{3}$

$$
\text { Installed wind capacity }=\frac{\text { Total wind energy }}{\text { Wind capacity factor } \times 8760 \text { hours }}
$$

Table 1 shows the installed wind capacity, peak demand and its SD, and installed fossil-fuel generation capacity for different wind energy penetrations considered. The installed fossil-fuel generation capacity is determined through a probabilistic approach using a 95\% reliability criterion. Such criterion implies that there is sufficient

\footnotetext{
${ }^{3}$ In practice, wind capacity factor may decrease as wind penetration increases as the 'best' wind sites are taken and only lower wind speed sites remain. Alternatively, it is also possible that advances in wind turbines might continue to improve capacity factors of newer farms.
} 
conventional generation capacity to meet the expected residual demand for each wind penetration for at least $95 \%$ of the 10,000 simulated years. Given a normal distribution of peak demand, a $95 \%$ reliability criterion is translated to $1.96 \mathrm{SD}$ above the expected peak demand.

Table 1: Installed Wind Capacity, Peak demand and Installed Conventional Generation Capacity for Different Wind Penetrations.

\begin{tabular}{lcccc}
\hline $\begin{array}{l}\text { Wind } \\
\text { penetration }\end{array}$ & $\begin{array}{c}\text { Installed wind } \\
\text { capacity (MW) }\end{array}$ & $\begin{array}{c}\text { Peak demand on } \\
\text { the RLDC (MW) }\end{array}$ & $\begin{array}{c}\text { SD of peak } \\
\text { demand (MW) }\end{array}$ & $\begin{array}{c}\text { Installed fossil-fuel } \\
\text { capacity (MW) }\end{array}$ \\
\hline $0 \%$ & 0 & 14,861 & 594 & 16,026 \\
$5 \%$ & 1,263 & 14,506 & 580 & 15,643 \\
$10 \%$ & 2,527 & 14,202 & 568 & 15,316 \\
$15 \%$ & 3,790 & 13,933 & 557 & 15,026 \\
$20 \%$ & 5,053 & 13,673 & 547 & 14,745 \\
$25 \%$ & 6,317 & 13,412 & 536 & 14,463 \\
\hline
\end{tabular}

\subsection{Generator Data}

New entrant generation costs and characteristics of each technology considered in this study are obtained from (ACIL Tasman, 2008, 2009) as shown in Table 2.

Table 2: Generator Data.

\begin{tabular}{lcccc}
\hline & \multicolumn{4}{c}{ Technology } \\
\cline { 2 - 5 } & Coal & CCGT & OCGT & Wind \\
\hline Plant life (years) & 40 & 30 & 30 & 30 \\
Capital cost (\$Million/MW) & 2.5 & 1.4 & 1.0 & 2.6 \\
Fixed O\&M (\$/MW/yr) & 40,000 & 13,000 & 7,500 & 20,000 \\
Variable O\&M $(\$ / M W h)$ & 1.2 & 4.85 & 7.5 & 1.6 \\
Average Efficiency $(\%)$ & 34 & 52 & 31 & N/A \\
Heat Rate $(\mathrm{GJ} / \mathrm{MWh})$ & 10.590 & 6.922 & 11.612 & $\mathrm{~N} / \mathrm{A}$ \\
$\mathrm{CO}_{2}$ emission factor $\left(\mathrm{tCO}_{2} / \mathrm{MWh}\right)$ & 1.05 & 0.45 & 0.7 & 0 \\
Fuel price $(\$ / \mathrm{GJ})$ & 0.6 & 5.2 & 5.2 & 0 \\
\hline
\end{tabular}

\subsection{Stochastic Model of Uncertain Parameters}

Mean fuel prices are obtained from (ACIL Tasman, 2009) while their SD of gas and coal price used in this study is based on their historical trend which is estimated to be $30 \%$ and $10 \%$ of their respective mean value (Blyth, 2008; IEA, 2009b; Roques et al., 2008). These values are shown in Table 3.

Table 3: Mean and SD of Coal and Gas Price.

\begin{tabular}{lcc}
\hline$(\$ / G J)$ & Coal price & Gas price \\
\hline Mean & 0.6 & 5.2 \\
SD & 0.06 & 1.56 \\
\hline
\end{tabular}

Different scenarios of expected carbon prices are considered in order to explore the impact of carbon pricing on the expected overall industry generation cost, cost uncertainty and $\mathrm{CO}_{2}$ emissions of generation portfolios. The SD of carbon price is assumed at $50 \%$ of the expected value, reflecting the high uncertainty involved.

Correlations among fuel and carbon prices are also considered, as shown in Table 4. These correlations are based on historical trends in Europe and some assumptions, which are approximately in line with recent studies (Awerbuch and Yang, 2008; Jansen et al., 
2006; Yang and Blyth, 2007). Whilst not necessarily applicable to the actual fuel supply situation in the region being studies, they do highlight the importance of considering such factors in planning (Roques et al., 2008).

Table 4: Correlation Coefficients between Fuel and Carbon Prices.

\begin{tabular}{|c|c|c|c|}
\hline $\begin{array}{l}\text { Correlation } \\
\text { Coefficient } \\
\left(\rho_{i, j}\right)\end{array}$ & $\begin{array}{l}\text { Coal } \\
\text { price } \\
\left(\rho_{\text {coal }}\right)\end{array}$ & $\begin{array}{c}\text { Gas } \\
\text { price } \\
\left(\rho_{\text {gas }}\right)\end{array}$ & $\begin{array}{c}\text { Carbon } \\
\text { price } \\
\left(\rho_{\text {carbon }}\right)\end{array}$ \\
\hline Coal price $\left(\rho_{\text {coal }}\right)$ & 1 & 0.65 & -0.32 \\
\hline Gas price $\left(\rho_{\text {gas }}\right)$ & 0.65 & 1 & 0.45 \\
\hline Carbon price $\left(\rho_{\text {carbon }}\right)$ & -0.32 & 0.45 & 1 \\
\hline
\end{tabular}

Correlated samples of gas, coal and carbon prices are generated from their marginal lognormal distributions using the multivariate Monte Carlo simulation procedure. Multivariate simulations reproduce random variables while preserving their marginal distribution properties and correlation structure (Chang et al., 1994). For each scenario of the expected carbon price, 10,000 samples of correlated fuel and carbon prices are generated. Fig. 4 shows the distribution of coal and gas prices and their scatter plot of 10,000 MCS runs highlighting their positive correlations.

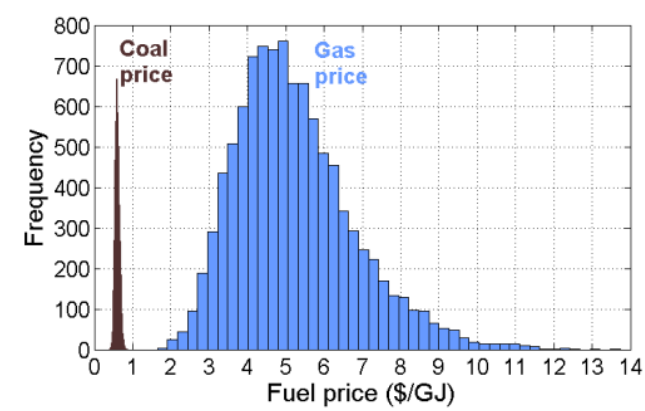

(a)

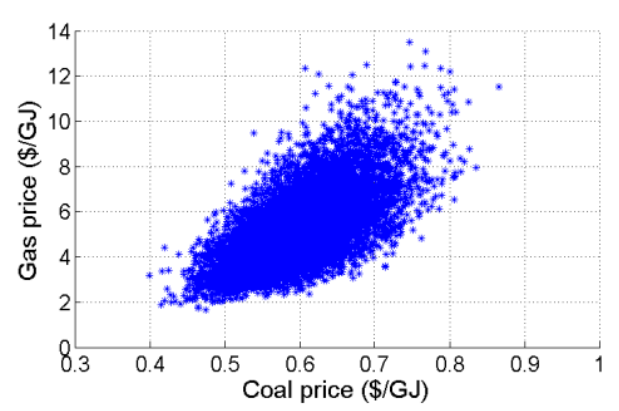

(b)

Fig. 4. (a) Distributions of coal and gas prices and (b) Scatter plot of coal and gas prices over 10,000 Monte-Carlo simulations indicating their positive correlation.

Demand uncertainty is modeled as the uncertainties in the RLDC for each wind penetration level. Each sample RLDC is derived based on each sample of residual peak demand for each wind penetration level. Samples of residual peak demand are generated from its probability distribution with mean and SD as indicated in Table 1 . The difference between a sample peak demand and the reference peak demand is then used to adjust the demand in every period of the reference RLDC. The uncertainty in the RLDC is modeled as vertical shifts in the reference RLDC thus maintaining the same shape and steepness. Adding uncertainty in the shape of RLDC is a possible extension to this approach. With this approach, the uncertainty in the RLDC is, to some extent, translated into uncertainty in the aggregated wind generation.

Samples RLDCs for different wind penetrations over 10,000 simulations are shown in Fig. 5. There are some instances when the simulated residual peak demands exceed the installed conventional generation capacity, resulting in energy not being served. The value of energy not served used in this study is $\$ 12,500 / \mathrm{MWh}$, which is the current market price cap for the Australian National Electricity Market (NEM) (AEMO, 2010). The cost of energy not served is included in the overall industry generation cost during 
each Monte Carlo run.
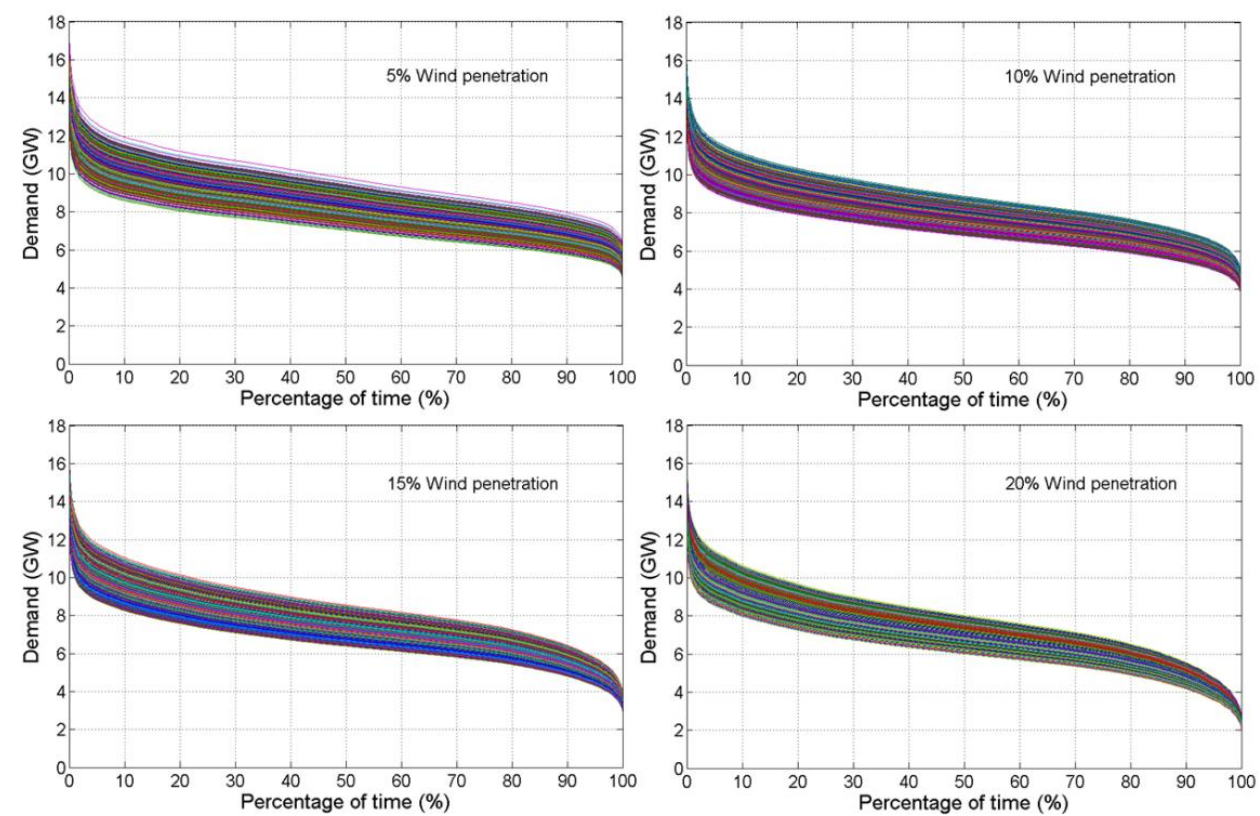

Fig. 5. Simulated RLDCs over 10,000 Monte-Carlo runs for each case of wind penetration.

The mean capital costs of each technology are obtained from (ACIL Tasman, 2008, 2009), while their SD are determined from a range of capital costs of each technology presented in (IEA/NEA, 2005, 2010). The SD of capital cost for Coal, CCGT, OCGT and Wind is estimated to be $15 \%, 10 \%, 5 \%$ and $5 \%$ of their mean capital costs respectively, and are shown in Table 5. Although the expected capital cost of wind power is high, it is assumed that its capital cost spread is relatively low since wind turbines can be installed quickly. The SD of wind plants is approximately in line with a number of studies (Awerbuch and Berger, 2003; Delarue et al., 2011). The capital cost distributions of each technology over 10,000 simulations are shown in Fig. 6.

Table 5: Mean and SD of Capital Costs.

\begin{tabular}{lcccc}
\hline (\$Million/MW) & Coal & CCGT & OCGT & Wind \\
\hline Mean & 2.5 & 1.4 & 1 & 2.6 \\
SD & 0.375 & 0.14 & 0.05 & 0.13 \\
\hline
\end{tabular}
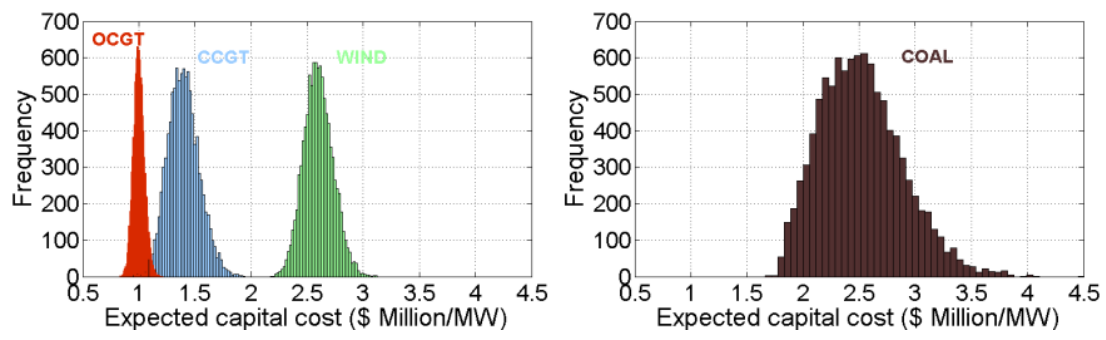

Fig. 6. Distribution of capital costs for different generation technologies.

These samples of correlated fuel and carbon prices, demand and capital costs are used for calculating the expected generation cost, cost uncertainty and $\mathrm{CO}_{2}$ emissions of each generation portfolio for different wind penetrations.

\section{Case Study Results And Analysis}

For each wind penetration, the calculation of overall industry costs and emissions 
for each generation portfolio is repeated for 10,000 simulated future fuel and carbon prices, demand, and capital costs. The impacts of carbon price and different wind penetrations on generation portfolios are also being explored.

\subsection{Expected cost, cost uncertainty and $\mathrm{CO}_{2}$ emissions for different wind penetrations}

Results for an expected carbon price of $\$ 30 / \mathrm{tCO}_{2}$ are used for illustrating the outputs from the tool. The expected annual generation cost, $\mathrm{CO}_{2}$ emissions and cost uncertainty of each of the possible thermal generation portfolios ${ }^{4}$ for $0 \%$ and $10 \%$ wind penetration scenarios are illustrated in Fig. 7. The expected generation costs are represented by the circles and the $\mathrm{CO}_{2}$ emissions of the corresponding portfolios are represented by the asterisks in the same vertical line. The efficient frontier $(\mathrm{EF})^{5}$ of optimal portfolios representing the lowest possible expected costs and cost uncertainty tradeoffs is shown in the solid line. Note that not every generation portfolio is presented on the graphs in order to expand the resolutions of the axes and aid clarity.

Different levels of wind penetrations can alter the optimal generation portfolios on the EF as shown in Fig. 7 (a) and (b). In this case, as the wind penetration increases from $0 \%$ to $10 \%$, the lowest cost generation portfolio changes from portfolio $A$ (50\% coal, $20 \%$ CCGT, 30\% OCGT) to portfolio $F$ (40\% coal, 20\% CCGT, 40\% OCGT). While the other optimal portfolios on the $\mathrm{EF}$ (portfolios $B, C, D$ and $E$ ) remain the same, the actual $\mathrm{EF}$ has moved diagonally upwards in the left direction which indicates higher overall expected industry costs but lower overall cost uncertainty.

The figure also suggests that the influence of wind penetration level depends on each particular generation portfolio. With higher wind penetration, the portfolios with a less share of coal tend to move closer to the EF indicating that they are becoming relatively more favorable in comparison with the portfolios with a larger share of coal. In the example shown in Fig. 7, although the overall expected industry generation cost increases as a result of the increase in wind penetration level (recall that wind generation has high capital costs despite its low operating costs), the overall cost uncertainty and $\mathrm{CO}_{2}$ emissions can be reduced quite significantly. This occurs since wind power has no fuel costs and does not emit carbon emissions, therefore it is not susceptible to fuel and carbon price fluctuations. The impact of wind penetration on the overall costs and associated cost uncertainty is analysed in detail in section 4.2 .

\footnotetext{
${ }^{4}$ These are the thermal generation plant portfolios for meeting net demand.

${ }^{5}$ Efficient Frontier (EF) is the concept used in the Mean Variance Portfolio (MVP) theory developed by (Markowitz, 1952) for financial portfolio optimisation. Along the EF, expected generation costs cannot be reduced without increasing the cost uncertainty and vice versa.
} 


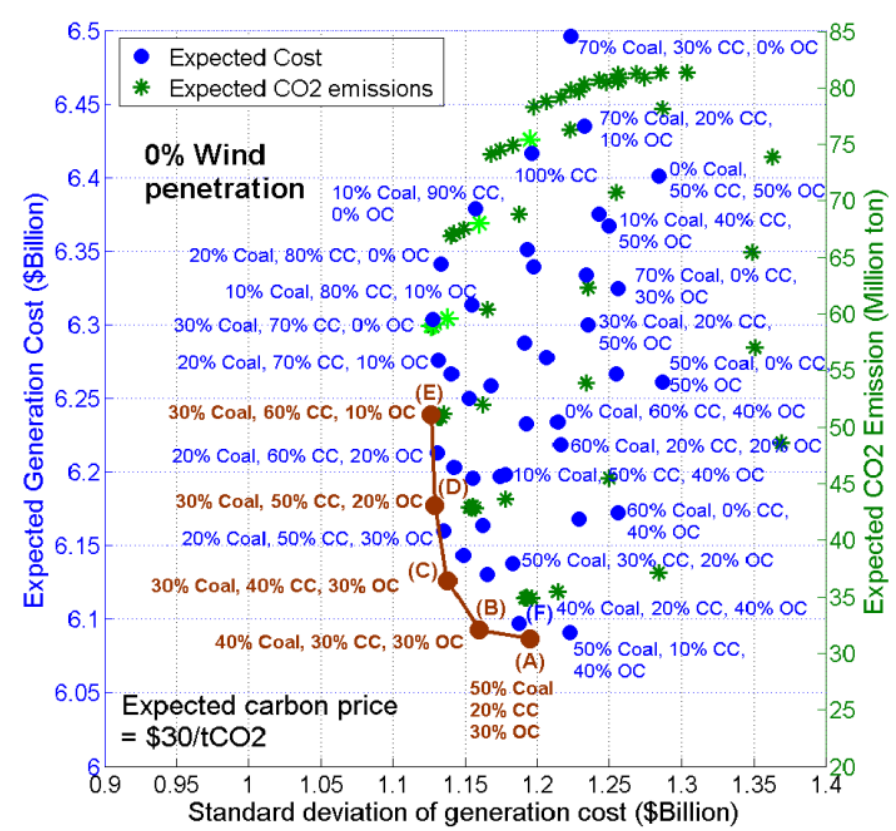

(a)

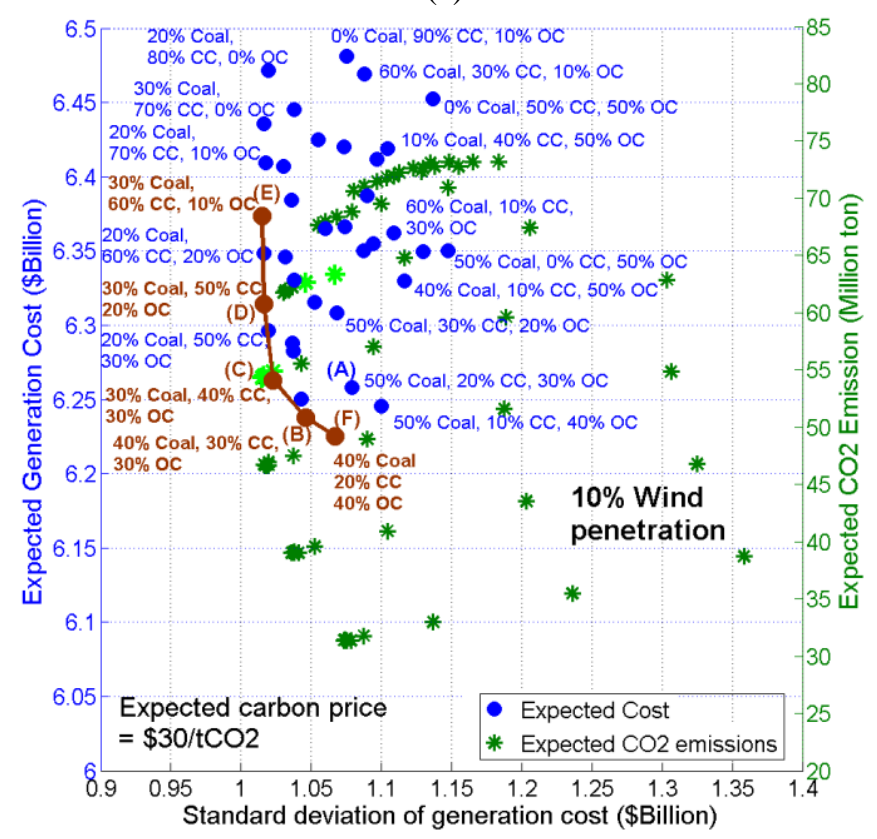

(b)

Fig. 7. Expected cost, cost uncertainty and $\mathrm{CO}_{2}$ emissions of generation portfolios for an expected carbon price of $\$ 30 / \mathrm{tCO}_{2}$ with (a) $0 \%$ wind penetration and (b) $10 \%$ wind penetration.

A full spectrum of possible generation costs of each portfolio can be displayed with a cost distribution plot. This is illustrated in Fig. 8, which shows normalised histogram and probability density of generation costs of some of the generation portfolios on the EF for $0 \%$ and $10 \%$ wind penetration for the case of an expected carbon price of $\$ 30 / \mathrm{tCO}_{2}$. These plots highlight the non-normality of the cost distributions and the impact of wind penetration on the cost spread of the portfolio.

Since the tool employs probabilistic portfolio analysis techniques, higher statistical moments $^{6}$, in addition to mean and variance, can also be considered. This is particularly

\footnotetext{
${ }^{6}$ Higher statistical moments include skewness and kurtosis. Skewness is a measure of asymmetry and kurtosis is a measure of the peakiness and tail fatness of a distribution. Skewness and kurtosis of a normal distribution are 0 and 3 respectively.
} 
important given the non-normality of the cost distributions. This aspect of the tool addresses one of the shortcomings of the standard generation portfolio analysis, which assumes that portfolio cost is represented by a normal distribution, and therefore only considers mean and variance. In addition, the tool is capable of analysing the tail behavior of the cost distributions in order to anticipate the magnitude of rare but high cost outcomes if the downside risk is of a main concern (Vithayasrichareon and MacGill, 2012a).
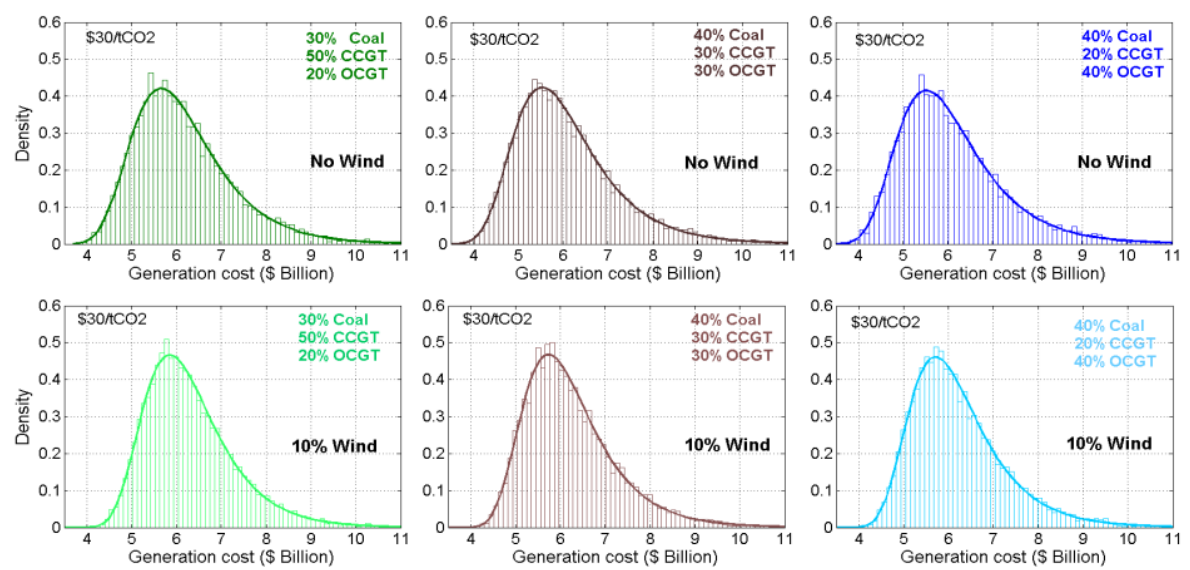

Fig. 8. Generation cost distribution of some of the portfolios on the EF for an expected carbon price of $\$ 30 / \mathrm{tCO}_{2}$ for the cases of $0 \%$ and $10 \%$ wind penetration.

Statistical parameters of the cost distributions of generation portfolios on or near the $\mathrm{EF}$ are shown in Table 6 for the case with $0 \%$ wind penetration and an expected carbon price of $\$ 30 / \mathrm{tCO}_{2}$. The table also shows the overall costs at the upper bound of the onesided $95 \%$ confidence interval, which in this particular example indicates the magnitude of rare but high cost outcomes. In this case, the skewness, kurtosis and the overall costs at the $95^{\text {th }}$ percentile among the optimal generation portfolios are not significantly different. However, these parameters can further enhance decision-making in choosing generation portfolios that suit particular risk preferences. For example, portfolio $A$ and $B$ have similar expected costs and comparable cost uncertainties but the tail characteristics of their cost distributions are quite different as indicated by the parameters shown in Table 6 . In this case, portfolio $B$ would arguably offer a more appropriate alternative to portfolio $A$ due to its less heavy tail, and potentially lower maximum probable cost in the case of rare but high cost outcomes at the $95^{\text {th }}$ percentile. The anticipated maximum probable cost of generation portfolios at any particular confidence interval can also be determined from the cost distributions.

Table 6. Statistical parameters of generation portfolios for the case without wind generation for a carbon price of $\$ 30 / \mathrm{tCO}_{2}$.

\begin{tabular}{lccccc}
\hline Portfolio & $\begin{array}{c}\text { Mean }(\mu) \\
(\$ B i l l i o n)\end{array}$ & $\begin{array}{c}\text { SD }(\sigma) \\
(\$ B i l l i o n)\end{array}$ & Skewness & Kurtosis & $\begin{array}{c}\text { Cost at the 95 }^{\text {th }} \\
\text { Percentile }(\$ B i l l i o n)\end{array}$ \\
\hline (A) 50\% Coal, 20\% CC, 30\% OC & 6.08 & 1.20 & 1.23 & 6.20 & 8.37 \\
(B) 40\% Coal, 30\% CC, 30\% OC & 6.09 & 1.16 & 1.26 & 5.91 & 8.32 \\
(C) 30\% Coal, 40\% CC, 30\% OC & 6.13 & 1.14 & 1.17 & 5.56 & 8.30 \\
(D) 30\% Coal, 50\% CC, 20\% OC & 6.18 & 1.13 & 1.15 & 5.45 & 8.33 \\
(E) 30\% Coal, 60\% CC, 10\% OC & 6.24 & 1.13 & 1.13 & 5.38 & 8.38 \\
(F) 40\% Coal, 20\% CC, 40\% OC & 6.10 & 1.12 & 1.29 & 6.07 & 8.37 \\
\hline
\end{tabular}


Fig. 9 shows that, generally, as wind penetration increases, the expected cost of most of the generation portfolios also increase. Interestingly, however, there are some portfolios where expected costs decrease or increase only very slightly with higher wind penetration. The expected generation costs of portfolios which contain a majority of OCGT (greater than $60 \%$ ) reduce or increase only very slightly with increasing wind penetration. In these cases, the variable operating costs of the generation portfolios are very high and, indeed, greater than the fixed costs. Hence, the reduction in variable cost of such portfolios with wind exceeds the increase in fixed costs resulting in a reduction in the overall expected cost. Since the level of carbon price affects the proportion of variable costs in the different portfolios, the impact of carbon pricing and wind penetration is examined further in the next section.

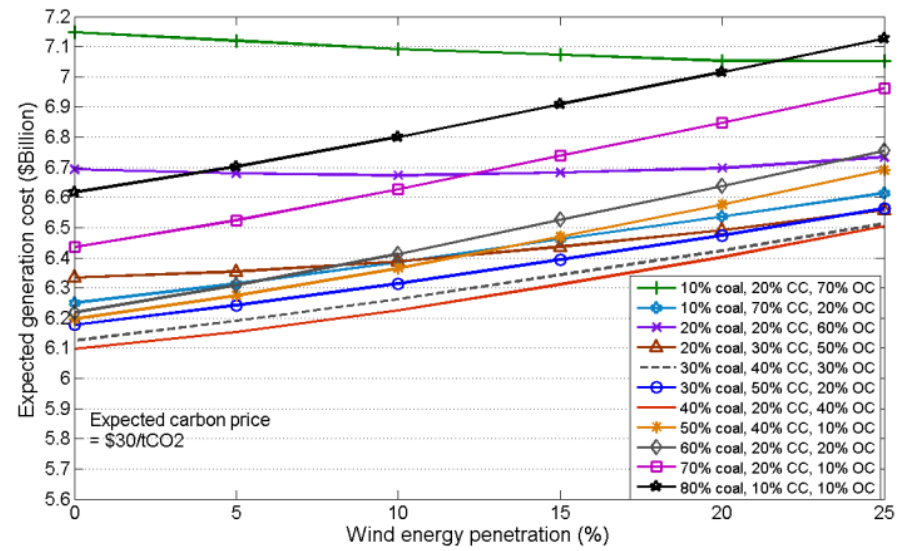

Fig. 9. Expected generation cost of some selected generation portfolios for different wind penetrations for an expected carbon price of $\$ 30 / \mathrm{tCO}_{2}$.

The results also suggest that increased wind penetrations can generally reduce the overall $\mathrm{CO}_{2}$ emissions of every generation portfolio quite considerably. For every generation portfolio, the reduction in $\mathrm{CO}_{2}$ emissions is around the same rate as the increase in wind penetration, as shown in Fig. 10.

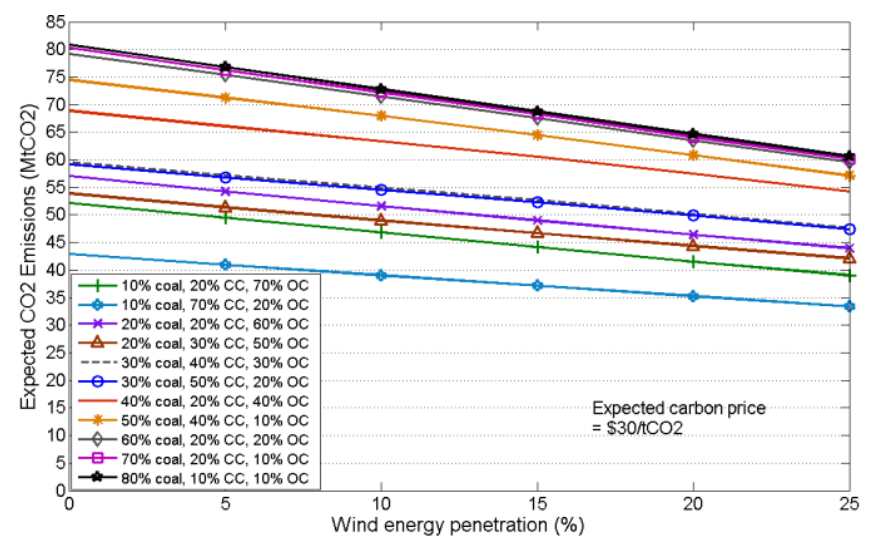

Fig. 10. Expected $\mathrm{CO}_{2}$ emissions of generation portfolios for different wind penetrations for an expected carbon price of $\$ 30 / \mathrm{tCO}_{2}$.

\subsection{The Impact of Carbon Pricing and Wind Penetration}

Results are also simulated for different scenarios of expected carbon prices, ranging from $\$ 0 / \mathrm{tCO}_{2}$ to $\$ 100 / \mathrm{tCO}_{2}$ in order to gain some high-level insights into the potential impact of carbon pricing and wind penetration levels on the expected industry cost, cost 
uncertainty and $\mathrm{CO}_{2}$ emissions.

\subsubsection{Impacts on overall industry cost and cost uncertainty}

The EFs showing the expected cost and cost uncertainty tradeoffs among the optimal generation portfolios for the different expected carbon prices and wind penetrations are shown in Fig. 11. For the expected carbon price between $\$ 0$ and $\$ 50 / \mathrm{tCO}_{2}$, it appears that increasing wind penetration would lead to higher overall expected cost but lower cost uncertainty.

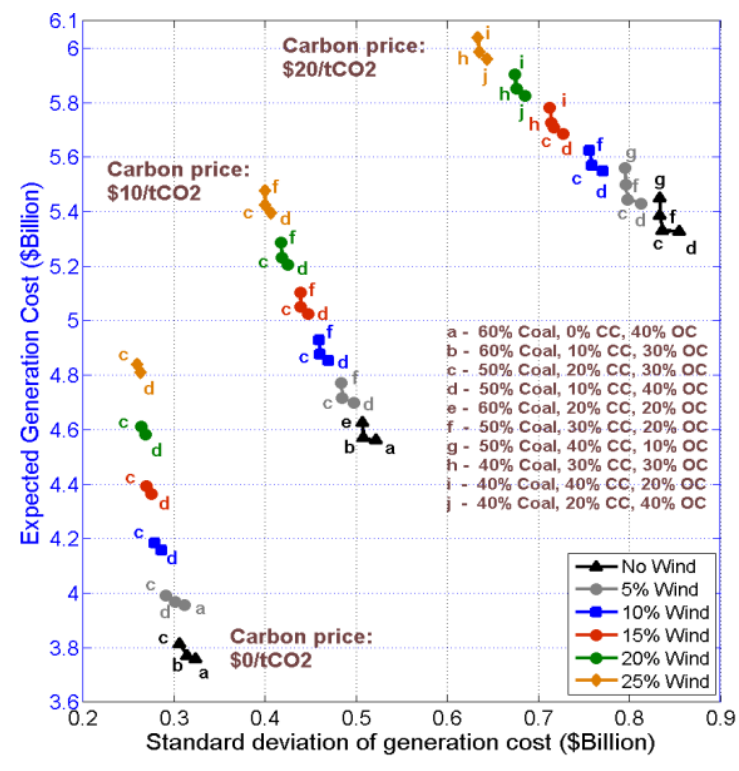

(a)

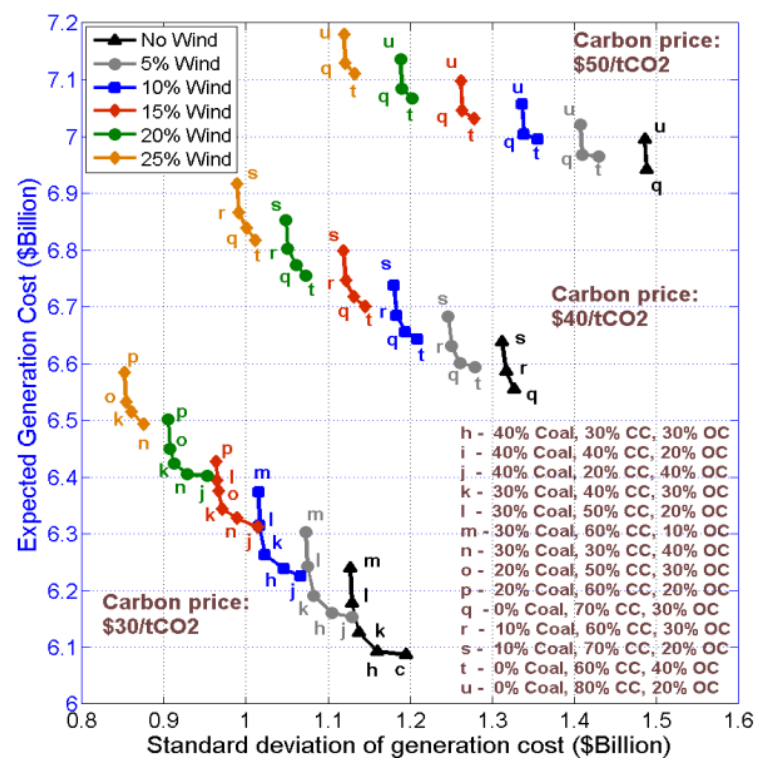

(b)

Fig. 11. Efficient frontiers for carbon prices of (a) $\$ 0, \$ 10$, and $\$ 20 / \mathrm{tCO}_{2}$ and (b) $\$ 30, \$ 40$ and $\$ 50 / \mathrm{tCO}_{2}$ for different wind penetrations.

As carbon price increases, the EFs move diagonally upwards, which implies an increase in both the overall industry expected cost and cost uncertainty. The generation portfolios which have a considerable share of coal are replaced by the portfolios with a lesser share of coal on the EF. For example, as the expected carbon price increases from $\$ 30$ to $\$ 40 / \mathrm{tCO}_{2}$, the least expected cost generation portfolio changes from $50 \%$ coal, $20 \%$ CCGT, 30\% OCGT to 0\% coal, 70\% CCGT, 30\% OCGT for the case of $0 \%$ wind penetration. Generally, an increase in the carbon price leads to an increase in the overall expected cost. However, for higher carbon prices, the increases in the expected cost as a result of increased wind penetration are smaller than when the levels of carbon price are moderate. It also shows that when the carbon price is high, the differences in cost uncertainty are more significant than the differences in expected cost as wind penetration increases. Interestingly, the lowest expected cost portfolios for all of the carbon prices and wind penetration scenarios contain a sizable share (40\%) of OCGT. For higher wind penetrations and carbon prices, the proportion of generation shifts from coal to CCGT in the optimal generation portfolios. Furthermore, and as noted earlier, increased wind penetrations can significantly reduce future cost uncertainty. 

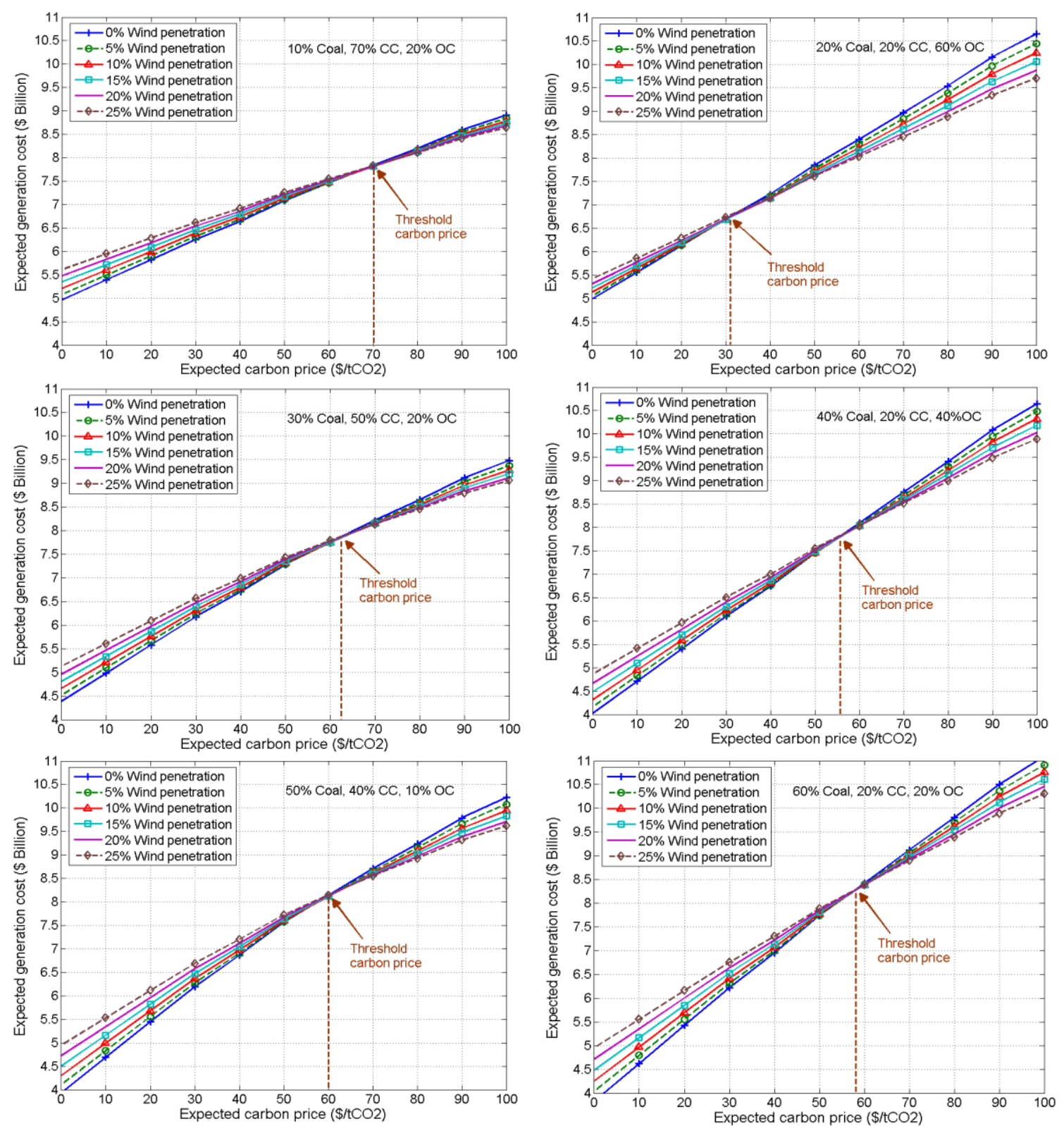

Fig. 12. Expected generation cost for different carbon prices and wind penetrations for some selected thermal generation portfolios.

As previously discussed, the impact of wind penetration on the expected cost of generation portfolios seems to depend on the level of carbon price and the types of technology mix in the portfolios. Fig. 12 shows the plots of the expected industry costs of some of the generation portfolios for different carbon prices and for different wind penetrations. From the figure, the overall portfolio generation cost generally increases with increasing wind penetrations. However, such increases in cost, as a result of higher wind penetration, become smaller as the carbon price increases. When a carbon price reaches a certain level (threshold carbon price), the overall portfolio costs begin to decrease with increasing wind penetration. The level of threshold carbon price appears to be particularly influenced by the proportion of OCGT in the portfolio. Generally, the threshold carbon prices for generation portfolios with a large share of OCGT are lower than those with a smaller share of OCGT. For example, and as shown in Fig. 12, the threshold carbon price of the $40 \%$ coal, $20 \%$ CCGT and $40 \%$ OCGT portfolio is about 
$\$ 55 / \mathrm{tCO}_{2}$ whereas the threshold carbon price is around $\$ 30 / \mathrm{tCO}_{2}$ for $20 \%$ coal, $20 \%$ CCGT and $60 \%$ OCGT portfolio.

The plots in Fig. 12 also suggest it is possible that overall industry costs would fall with higher wind penetration if the carbon price is sufficiently high. Such effects were not evidenced in Fig. 11 since it only shows the EFs for carbon price up to $\$ 50 / \mathrm{tCO}_{2}$. EFs for carbon prices higher than $\$ 50 / \mathrm{tCO}_{2}$ are therefore plotted in Fig. 13 to observe this effect. The figure shows that when a carbon price reaches $\$ 70 / \mathrm{tCO}_{2}$, increasing wind penetration does not necessarily increase the overall industry costs while the cost uncertainty continues to decrease. As the carbon price reaches $\$ 80 / \mathrm{tCO}_{2}$, it is apparent that the EFs get shifted downwards with increased wind penetration implying lower expected industry costs and cost uncertainty. Therefore, for this case study, the value of wind generation in terms of reducing the overall industry cost and hedge against the cost uncertainty is maximised if the carbon price is greater than $\$ 70 / \mathrm{tCO}_{2}$.

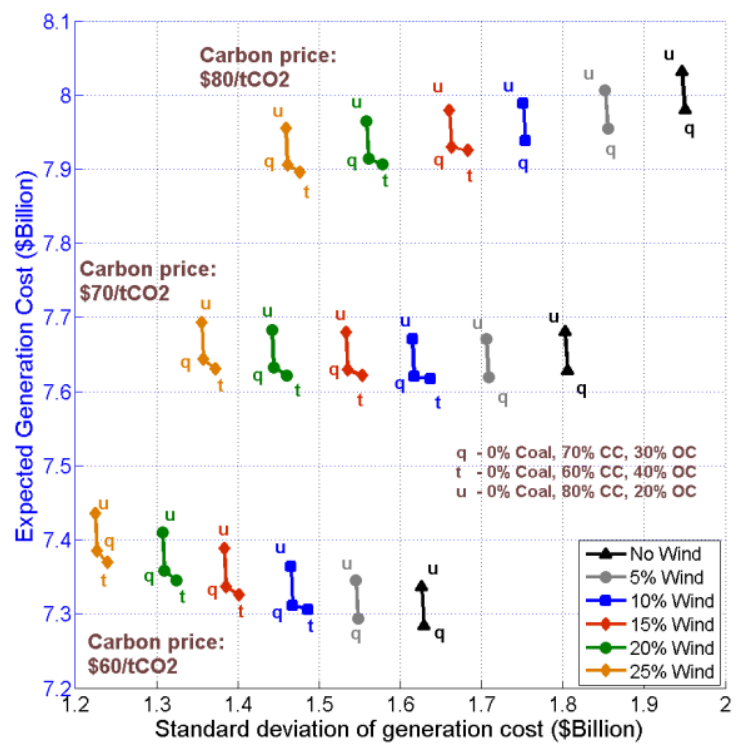

Fig. 13. Efficient frontiers for carbon prices of $\$ 60, \$ 70, \$ 80 / \mathrm{tCO}_{2}$ for different wind penetrations.

Higher carbon prices increase the proportion of variable costs in relation to fixed costs of generation portfolios. With low or moderate level of carbon prices (i.e. below $\$ 50 / \mathrm{tCO}_{2}$ ), generation portfolios which consist mainly of coal and CCGT have a higher proportion of fixed costs than variable cost. Therefore, the increase in fixed cost of these portfolios is more significant than the reduction in variable cost as wind penetration increases. For these portfolios, the carbon price needs to be quite high in order for the overall cost to reduce with increasing wind penetration. The level of carbon price and the mix of conventional plant are, therefore, highly influential factors on the economic value of wind power within an electricity industry.

\subsubsection{The impact of carbon pricing on $\mathrm{CO}_{2}$ emissions}

The plot of the expected $\mathrm{CO}_{2}$ emissions of various generation portfolios for different carbon prices in the case of $5 \%$ wind penetration is shown in Fig. 14. Without modelling uncertainty, these plots of $\mathrm{CO}_{2}$ emissions typically take the form of step functions since reductions in $\mathrm{CO}_{2}$ emissions occur at a carbon price at which the operating costs of plant change with respect to each other sufficiently to change the merit 
order of dispatch. However, when uncertainty is considered in the assessment, expected $\mathrm{CO}_{2}$ emissions, instead, change smoothly as carbon price increases as shown in the figure.

The impact of carbon price on $\mathrm{CO}_{2}$ emissions varies according to the share of each thermal generation technology in the portfolio. Portfolios with a dominant technology in the mix cannot achieve significant emissions reductions regardless of carbon price. Portfolios with a relatively even mix across coal and CCGT have comparatively higher $\mathrm{CO}_{2}$ emissions at low carbon prices than predominantly gas portfolios, but the reduction in $\mathrm{CO}_{2}$ emissions of these portfolios tends to be more rapid with increasing carbon prices. These impacts are the same for higher wind penetrations but only move down the plots of $\mathrm{CO}_{2}$ emissions of every portfolio.

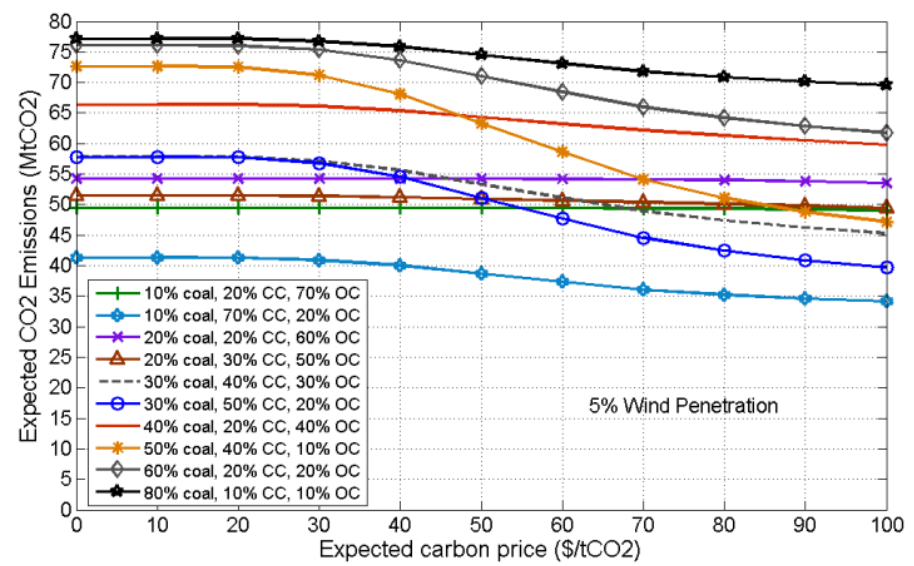

Fig. 14. $\mathrm{CO}_{2}$ emissions of different generation portfolios for different carbon prices for the case of $5 \%$ wind penetration.

\section{Policy Implications}

The case study results highlight a number of policy-related issues, particularly associating with the level of future carbon price and wind penetration, which are valuable for generation planning and policy decision-making in the electricity industry. The results suggest that there are potentially complex interactions between wind penetration levels and carbon pricing on the expected generation costs, associated cost uncertainties and $\mathrm{CO}_{2}$ emissions of different conventional plant portfolios.

Regardless of the level of carbon price, wind generation can significantly help reducing the overall $\mathrm{CO}_{2}$ emissions from the electricity industry given its zero emissions. Hence, wind power will significantly contribute towards a future low-carbon electricity industry. The results also strengthen the view that wind power can play an important role in hedging against future fossil fuel and carbon price volatility since increasing the level of wind penetration will reduce the cost uncertainty of all conventional generating plant portfolios.

Another important policy-related issue is the economic value of wind generation in future electricity industries, which was found to be primarily influenced by the level of carbon price and the particular portfolio of conventional generation plant within the electricity industry. When carbon prices are low or moderate, high wind penetrations increase overall expected generation costs. However, when carbon prices are high, increasing wind penetration can potentially reduce overall expected generation cost. This 
is due to wind's high capital cost but 'free' fuel. Hence, a sufficiently high carbon price would maximise the value of wind generation by reducing the overall industry generation cost. The extent to which wind generation affects the expected cost and exposure to risk for portfolios depends on their proportion of fixed and variable costs. The case study highlighted the synergies between OCGT and wind generation under all carbon prices, suggesting that peaking plants can play a valuable role in reducing the overall costs and cost uncertainties of generation portfolios that consist of wind generating plants.

Although the case study data is Australian specific, the results do highlight the potential implications of different wind penetrations and carbon prices on the expected costs, associated cost uncertainties and $\mathrm{CO}_{2}$ emissions of a largely conventional coal and gas fueled electricity industry, which has relevance for policy decision-making for many electricity industries around the world.

\section{Conclusions}

This paper demonstrates the application of a Monte Carlo simulation based decision-support tool to perform high level analysis of the costs, risks and greenhouse emissions of possible thermal generation plant portfolios in the context of varying wind penetrations and carbon prices. The technique incorporates half-hourly wind data and electricity demand to create a Residual Load Duration Curve (RLDC) under different wind penetrations. A stochastic MCS extension to standard optimal generation mix methods and the use of portfolio-based technique allows the tool to provide estimated overall generation costs, associated cost uncertainty, and industry greenhouse emissions for different possible thermal plant portfolios and wind penetrations. As such, the tool extends the capabilities of some of the key methods currently used to make such portfolio assessments. In addition, the case study results demonstrate that the tool can provide highlevel insights into a number of policy-related issues within the electricity industry, particularly relating with future carbon pricing and the level of wind generation in future generation portfolios.

The tool was demonstrated on a case study based on wind generation and demand within South Eastern Australia, and conventional coal, CCGT and OCGT generation options under uncertain future coal and gas prices, carbon price, electricity demand and plant capital costs. Historical data and independent expert opinion were used, with uncertainties modeled through log-normal and normal distributions. However, a great strength of this approach is that far more complex probability distributions can be used.

The results suggest that wind generation can play a valuable role in reducing carbon emissions from the electricity industry as well as hedging against uncertain future fossil prices and carbon pricing policies. Increasing wind penetration does not always necessarily lead to an increase in the cost of generation portfolios. It has been demonstrated that the value of wind generation in future generation portfolios is influenced by two primary factors: the level of future carbon price and the particular mix of conventional generation technologies within the electricity industry.

Despite the capability of the tool, there are some notable limitations and hence areas for potential extension. As noted earlier, the tool adopted an overall electricity industry 
societal perspective focusing on the overall industry costs. Hence it could be extended to consider issues relating with restructured electricity industries by taking account individual investment decisions as well as incorporating the degree of risk aversion and risk preferences. Since the tool is based on the use of the LDC and RLDC techniques, they remove the chronology and hence ignore inter-temporal operational implications associated with different possible generation portfolios. These aspects, for example, include unit commitment, ramp rate constraints, and network constraints. Whilst the focus of the tool is on high-level portfolio assessments involving future uncertainties, there do appear to be some opportunities to consider some important operational issues within the assessment. Such limitation will be addressed is future work. Although this paper assessed completely new-build generation portfolios to meet future demand, the approach taken by the tool can incorporate existing generating plant within possible future portfolios in order to assess new plant investment options.

\section{Acknowledgment}

The authors would like to thank Dr. Nicholas Cutler for his help with the NEM data and Dr. Paul Twomey for his helpful suggestions on this paper.

\section{REFERENCES}

ACIL Tasman, 2008. Projected energy prices in selected world regions. Acil Tasman

ACIL Tasman, 2009. Fuel resource, new entry and generation costs in the NEM. ACIL Tasman

AEMO, 2009a. Electricity Statement of Opportunities for the National Electricity Market. Australian Energy Market Operator Available at http://www.aemo.com.au/planning/0410-0006.pdf.

AEMO, 2009b. National Electricity Market (NEM) data. Australian Energy Market Operator.

AEMO, 2010. An Introduction to Australia's National Electricity Market. Australian Energy Market Operator

Awerbuch, S., 2006. Portfolio-Based Electricity Generation Planning: Policy Implications For Renewables And Energy Security. Mitigation and Adaptation Strategies for Global Change 11, 693-710.

Awerbuch, S., Berger, M., 2003. Energy Security and Diversity in the EU: a Mean-Variance Portfolio approach. IEA Research Paper

Awerbuch, S., Yang, S., 2008. Efficient Electricity Generating Portfolios for Europe: Maximizing Energy Security and Climate Change Mitigation, in: Bazilian, M., Roques, F. (Eds.), Analytical Methods for Energy Diversity and Security: A tribute to Shimon Awerbuch. Elsevier, London, pp. 87-115.

Blyth, W., 2008. Use of Real Options as a Policy Analysis Tool, in: Bazilian, M., Roques, F.A. (Eds.), Analytical Methods for Energy Diversity and Security. Elsevier, London, pp. 69-83.

Bushnell, J., 2010. Building Blocks: Investment in Renewable and Non-Renewable Technologies. Energy Institute at Haas Working Paper \#202

Chang, C.-H., Tung, Y.-K., Yang, J.-C., 1994. Monte Carlo Simulation for Correlated Variables with Marginal Distributions. Journal of Hydraulic Engineering 120, 313-331.

De Jonghe, C., Delarue, E., Belmans, R., D’haeseleer, W., 2011. Determining optimal electricity technology mix with high level of wind power penetration. Applied Energy 88, 2231-2238.

Delarue, E., De Jonghe, C., Belmans, R., D'Haeseleer, W., 2011. Applying portfolio theory to the electricity sector: Energy versus power. Energy Economics 33, 12-23.

Doherty, R., Outhred, H., O'Malley, M., 2006. Establishing the Role That Wind Generation May Have in Future Generation Portfolios. IEEE Transactions on Power Systems 21, 1415-1422. 
Duenas, P., Reneses, J., Barquin, J., 2011. Dealing with multi-factor uncertainty in electricity markets by combining Monte Carlo simulation with spatial interpolation techniques. Generation, Transmission \& Distribution, IET 5, 323-331.

Electricity Supply Industry Planning Council (ESIPC), 2004. Planning Council Wind Report to ESCOSA.

EWEA, 2011. Wind in power: 2010 European statistics. The European Wind Energy Association

Eydeland, A., Wolyniec, K., 2003. Energy and Power Risk Management. John Wiley \& Sons, Hoboken, New Jersey.

Gotham, D., Muthuraman, K., Preckel, P., Rardin, R., Ruangpattana, S., 2009. A load factor based mean-variance analysis for fuel diversification. Energy Economics 31, 249-256.

Huang, Y.-H., Wu, J.-H., 2008. A portfolio risk analysis on electricity supply planning. Energy Policy 36, 627-641.

IEA, 2007. Climate Policy Uncertainty and Investment Risk. International Energy Agency, Paris.

IEA, 2009a. CO2 Emissions from Fuel Combustion, 2009 Edition. International Energy Agency, Paris.

IEA, 2009b. Electricity Information 2009. International Energy Agency, Paris.

IEA/NEA, 2005. Projected Costs of Generating Electricity, 2005 Update. International Energy Agency, Paris. Paris.

IEA/NEA, 2010. Projected Costs of Generating Electricity 2010 Edition. International Energy Agency,

Jansen, J.C., Beurskens, L.W.M., Tilburg, X.V., 2006. Application of portfolio analysis to the Dutch generating mix. Energy research council of Netherlands ECN report C-05-100

Joskow, P.L., 2010. Comparing the costs of intermittent and dispatchable generating technologies. Center for Energy and Environmental Policy Research. MIT Working paper 10-013

MacGill, I., 2010. Electricity market design for facilitating the integration of wind energy: Experience and prospects with the Australian National Electricity Market. Energy Policy 38, 3180-3191.

Madlener, R., Wenk, C., 2008. Efficient Investment Portfolios for the Swiss Electricity Supply Sector. FCN Working Paper No. 2/2008

Markowitz, H., 1952. Portfolio Selection. The Journal of Finance 7, 77-91.

Milligan, M., Lew, D., Corbus, D., Piwko, R., Miller, N., Clark, K., Jordan, G., Freeman, L., Zavadil, B., Schuerger, M., 2009. Large-Scale Wind Integration Studies in the United States: Preliminary Results; Preprint. National Renweable Energy Laboratory Available at http://www.osti.gov/bridge/servlets/purl/964211-NCqvvR/.

Newcomer, A., Blumsack, S.A., Apt, J., Lave, L.B., Morgan, M.G., 2008. Short Run Effects of a Price on Carbon Dioxide Emissions from U.S. Electric Generators. Environmental Science \& Technology 42, 3139-3144.

Roques, F.A., Newbery, D.M., Nuttall, W.J., 2008. Fuel mix diversification incentives in liberalized electricity markets: A Mean-Variance Portfolio theory approach. Energy Economics 30, 1831-1849.

Roques, F.A., Nuttall, W.J., Newbery, D., 2006. Using Probabilistic Analysis to Value Power Generation Investments under Uncertainty. EPRG Working Paper 065

Savvides, S.C., 1994. Risk Analysis in Investment Appraisal. Project Appraisal 9, 3-18.

Smith, J.C., Milligan, M.R., DeMeo, E.A., Parsons, B., 2007. Utility Wind Integration and Operating Impact State of the Art. IEEE Transactions on Power Systems 22, 900-908.

Spinney, P.J., Watkins, G.C., 1996. Monte Carlo simulation techniques and electric utility resource decisions. Energy Policy 24, 155-163.

Traber, T., Kemfert, C., 2011. Gone with the wind? - Electricity market prices and incentives to invest in thermal power plants under increasing wind energy supply. Energy Economics 33, 249-256.

Tuohy, A., Meibom, P., Denny, E., O'Malley, M., 2009. Unit Commitment for Systems With Significant Wind Penetration. IEEE Transactions on Power Systems 24, 592-601. 
Ummels, B.C., Gibescu, M., Pelgrum, E., Kling, W.L., Brand, A.J., 2007. Impacts of Wind Power on Thermal Generation Unit Commitment and Dispatch. IEEE Transactions on Energy Conversion 22, 44-51.

Vithayasrichareon, P., MacGill, I.F., 2012a. A Monte Carlo based decision-support tool for assessing generation portfolios in future carbon constrained electricity industries. Energy Policy 41, 374-392.

Vithayasrichareon, P., MacGill, I.F., 2012b. Portfolio assessments for future generation investment in newly industrializing countries - A case study of Thailand. Energy 44, 1044-1058.

Yang, M., Blyth, W., 2007. Modelling Investment Risks and Uncertainties with Real Options Approach. International Energy Agency A working paper for an IEA book: Climate Policy Uncertainty and Investment Risk 